\title{
Educação Intergeracional como promotora do envelhecimento ativo: Estudo de uma comunidade local
}

\author{
Susana Villas-Boas. Universidade de Coimbra (Portugal) \\ Albertina Lima Oliveira. Universidade de Coimbra (Portugal) \\ Natália Ramos. Universidade Aberta de Lisboa (Portugal) \\ Inmaculada Montero. Universidad de Granada (Spain)
}

\section{Recepción: 27 de febrero de 2017 | Aceptado: 6 de marzo de 2017 Correspondencia: Susana Villas-Boas | Correo-e: uc42665@uc.pt}

\author{
(iD 0000-0003-3937-3229 \\ Citar: Villas-Boas, S., Lima, A., Ramos, N., e Montero, I. (2017). Educação Intergeracional \\ como promotora do envelhecimento ativo: Estudo de uma comunidade local. ReiDoCrea, 6, \\ 105-119.
}

\begin{abstract}
Resumo: As autoras investigam a atividade de uma amostra de 385 residentes na freguesia do Bonfim da cidade do Porto, com o objetivo de compreender as necessidades desta população para a promoção do envelhecimento ativo através da educação intergeracional. Com base nas análises quantitativas realizadas, numa perspetiva comparativa entre diferentes grupos etários e diferentes características sociodemográficas, concluiu-se, por um lado, que a participação na sociedade da amostra estudada é média-baixa e que as atividades de lazer realizadas com mais frequência são atividades fisicamente mais passivas e frequentemente praticadas de forma individual. Por outro lado, evidenciou-se que as pessoas mais ativas são os mais jovens, os homens, as pessoas com maiores níveis de escolaridade e maiores rendimentos. A informação e o conhecimento emergente deste estudo demonstram a necessidade de oferecer oportunidades de participação, de aumentar as atividades física, cognitiva e de lazer e o contacto social de todos os indivíduos, independentemente da idade e das características sociodemográficas, confirmando-se a pertinência de utilizar a educação intergeracional como estratégia de promoção deste novo paradigma de envelhecimento.
\end{abstract}

Palavras-chave: Educação permanente | Envelhecimento da sociedade

\section{La Educación Intergeneracional como promotora del envejecimiento activo: Estudio de la actividad de una comunidad local}

Resumen: En este estudio, las autoras investigaron la actividad de una muestra de 385 residentes de la población de la parroquia Bonfim ciudad de Oporto, con el objetivo de entender las necesidades de esta población para promover el envejecimiento activo a través de la educación intergeneracional. Las autoras presentan un análisis cualitativo y comparativo de los diferentes grupos de edad y diferentes características sociodemográficas. Concluyendo, por un lado, que la participación en la sociedad de la población de estudio es media-baja y que las actividades de ocio más realizadas son las actividades físicamente más pasivas y que se practican frecuentemente de forma individual. Por otro lado, las personas más activas son más jóvenes, hombres, con mayores niveles de educación e ingresos más altos. La información y el conocimiento emergente en este estudio, demuestra la necesidad de proporcionar oportunidades para la participación, de aumentar las actividades físicas, cognitivas y de ocio y el contacto social de todos los individuos, independientemente de la edad y de las características sociodemográficas, si lo que se pretende es proporcionar un envejecimiento activo y saludable de individuos y poblaciones. Al mismo tiempo, confirma la pertinencia de utilizar la educación intergeneracional como una estrategia para promover este nuevo paradigma de envejecimiento.

Palabras clave: Educación permanente | Envejecimiento de la sociedad

Intergenerational Education as a promoter of active ageing: $A$ study of the activity of a local community

Abstract: In this study the authors investigate the activity of a sample of 385 residents of Bonfim parish in the city of Oporto. The main goal was to understand the needs of this population for the promotion of active ageing through intergenerational education. Based on the qualitative analysis conducted from a comparative perspective between different age groups and different socio-demographic characteristics, it was concluded, on the one hand, that the participation in society of the sample studied is medium-low and 
that the leisure activities carried out most frequently are physically more passive activities and are often practiced individually. On the other hand, the analyses showed that the most active people are younger men, with higher levels of education and higher incomes. The knowledge and information emerging from this study demonstrates the need to provide opportunities for participation, to increase physical, cognitive and leisure activities as well as social contact among all individuals, regardless of age and sociodemographic characteristics, if the intention is to provide an increase in the active and healthy ageing of individuals and populations. In this context, the relevance of using intergenerational education as a strategy for promoting the new paradigm of active ageing is confirmed.

Keywords: Lifelong Education | Ageing Society

\section{Introdução}

O envelhecimento demográfico que se regista a nível mundial, acompanhado do prolongamento dos anos de vida dos indivíduos, impulsionou o início de um novo paradigma de envelhecimento - o envelhecimento ativo. Embora ainda não exista um consenso sobre o que se entende por envelhecimento ativo, por parte das organizações mundiais, o que tem dificultado o entendimento dos discursos e práticas sobre o mesmo e afetado a própria elaboração concetual (Moulert \& Paris, 2013), é hoje incontestável a necessidade da construção de um novo modelo de sociedade e de aprofundamento do paradigma de envelhecimento ativo.

No início do século XXI, a Organização Mundial a Saúde (OMS) definiu envelhecimento ativo como "o processo de otimização das oportunidades de saúde, participação e segurança, visando melhorar a qualidade de vida à medida que as pessoas envelhecem" (WHO, 2002, p.12). Esta definição concentra em si a ideia de que o envelhecimento é um processo que se desenrola à medida que as pessoas envelhecem, ou seja, que o envelhecimento não começa numa idade determinada cronologicamente, mas que é um fenómeno que se desenvolve ao longo do ciclo vital. A otimização referida na definição não pode deixar de atribuir relevância às experiências e às mudanças sofridas durante o ciclo vital do indivíduo, resultantes de fatores como as condições económicas, sociais, pessoais (biológicas e psicológicas), comportamentais, o acesso a serviços de saúde e a serviços sociais de apoio, o sexo e a cultura, os quais determinam a diversidade entre os indivíduos (que aumenta com a idade), e influenciam as diferentes trajetórias de saúde e envelhecimento de indivíduos e populações. Atendendo a este conjunto de fatores, a OMS considera que o envelhecimento é um processo biopsicossocial, em que as dimensões biológica, psicológica e social são entendidas como três processos paralelos interrelacionados. Logo, para fazer do envelhecimento uma experiência positiva é fundamental dar às pessoas oportunidades que permitam a realização do seu potencial de bem-estar físico, social e mental, ao longo da vida, salvaguardando, todavia, que a participação dos indivíduos na sociedade deve estar de acordo com as suas necessidades, desejos e capacidades. E, finalmente, a OMS apresenta como principais meios para a promoção do envelhecimento ativo, a aprendizagem ao longo da vida, a participação em atividades produtivas, incluindo as que estão fora do mercado de trabalho, e a participação em atividades saudáveis.

Uma estratégia que tem vindo a demonstrar bons resultados na promoção do envelhecimento ativo, é a que enquadra atividades, projetos e programas intergeracionais (Sánchez, 2009), através da qual se coloca a educação intergeracional em prática. Definimos a educação intergeracional como:

“Um processo pedagógico que coloca pessoas de diferentes gerações a executarem atividades e tarefas que respondem às suas necessidades e 
interesses, numa dinâmica de participação, cooperação, interação, intercâmbio e de diálogo intergeracional desenvolvido numa relação igualitária, de tolerância e respeito mútuo. Tem como principal finalidade facilitar e garantir que as pessoas de diferentes gerações aprendam, desenvolvam e compartilhem conhecimentos, competências, habilidades, atitudes e valores e se transformem na relação umas com as outras" (Villas-Boas, Oliveira, Ramos \& Montero, 2016, p.133)

O mais importante neste tipo de educação não é dar informação, mas sim participar conjuntamente na transmissão e criação de atitudes, sentimentos, pensamentos, sensações, por outras palavras, a educação intergeracional tem como finalidade construir processos recíprocos de orientação, influência, intercâmbio e aprendizagem entre os membros de duas ou mais gerações, ou seja, construir relações intergeracionais que facilitem e permitam a transmissão de valores, saberes e conhecimentos e, consequentemente, a transformação positiva das pessoas, das comunidades e, em última instância, da cultura (Saéz, 2002). Resumidamente, a educação intergeracional reúne pessoas com as mesmas necessidades e interesses, a realizarem atividades ou tarefas que não são estabelecidas a priori, mas resultam do debate e reflexão contínuas e conjunta entre os participantes, desde a sua seleção, passando pelo planeamento e respetiva implementação. As atividades intergeracionais, desenvolvidas num processo de comunicação dialógica assente numa relação igualitária, são atividades consideradas com sentido (Oliveira \& Portugal, 2016), ou seja, atividades que fomentam a "compreensão da vida pessoal (i. e., como o self se integra e funciona no mundo) e o propósito que motiva a atividade relevante; aquilo que dá coerência à vida, reunindo o passado, o presente e o futuro do indivíduo em continuidade" (Oliveira \& Portugal, 2016, p.5).

Este tipo de educação contribui para o alcance dos objetivos do envelhecimento ativo, na medida em que promove: i) a mudança de mentalidade em relação ao envelhecimento e a superação de estereótipos e preconceitos de idade, bem como outro tipo de preconceitos, contribuindo para fomentar o respeito pela diversidade e a construção de uma sociedade mais tolerante; ii) a mudança e a melhoria nas formas de relacionamento da pessoa consigo própria e com os outros; iii) a adoção de comportamentos e atitudes mais saudáveis e responsáveis; iv) o aumento da participação em questões sociais, cívicas, económicas, culturais, educativas e espirituais; v) o aprender sobre a história, as origens e a atualização de conhecimentos numa sociedade em constante mudança, vi) o estabelecimento de novas formas de solidariedade entre gerações, e outros (Kaplan, 2001; Maccallum et al., 2010). A educação intergeracional mostra-se assim como uma estratégia com grande potencial para a melhoria da qualidade de vida, saúde e bem-estar de indivíduos e populações e contribui para construção de um modelo de sociedade mais justo, mais solidário e com mais participação por parte dos cidadãos, isto é, para o envelhecimento ativo e digno de indivíduos e populações.

Tendo em conta o que referimos previamente, e entendendo a atividade, como atividade com sentido, ou seja, em sentido amplo, não se confinando à que é remunerada, mas incluindo toda a ocupação significativa que contribua para o bemestar do indivíduo, da sua família, da comunidade local e da sociedade em geral, no presente estudo empírico ${ }^{1}$ consideramos a participação social (sentido de participação) e as atividades de desenvolvimento pessoal e de lazer (sentido identitário) para identificar e compreender a atividade não remunerada de uma amostra da população da freguesia do Bonfim, da cidade do Porto, região norte de

\footnotetext{
${ }^{1}$ Este estudo faz parte de um estudo mais alargado sobre "A Educação Intergeracional como Estratégia de Promoção do Envelhecimento Ativo: Análise de necessidades de uma comunidade local, enquanto via fundamentadora de projetos relevantes e sustentáveis", cofinanciado pela Fundação para a Ciência e Tecnologia/FCT, Portugal.
} 
Portugal - informação fundamental para o plano e desenho de projetos, programas e atividades, que fomentem o envelhecimento ativo na comunidade.

\section{Método}

\section{Participantes}

Nesta investigação participaram 385 residentes da freguesia do Bonfim da cidade do Porto, com 15 e mais anos de idade, distribuídos pelos três seguintes grupos etários: os jovens e adultos jovens (42,9\%), adultos de meia-idade $(28,6 \%)$ e adultos idosos $(28,6 \%)$. A amostra global é constituída por $57,1 \%$ de pessoas do sexo feminino e $42,9 \%$ do sexo masculino. O nível de escolaridade mais representado é o $1^{\circ}$ ciclo completo $(27,3 \%)$, seguido do secundário $(19,2 \%)$, $3^{\circ}$ ciclo $(17,1 \%)$, póssecundário/Licenciatura $(15,4 \%), 2^{\circ}$ ciclo $(10,4 \%)$, menos de 4 anos de escolaridade $(6,2 \%)$, e, finalmente, pelos níveis de mestrado/doutoramento $(4,2 \%)$. Quanto ao nível socioeconómico $^{2}$, mais de metade da amostra $(54,5 \%)$ tem um rendimento mensal inferior ao rendimento médio nacional, $26,8 \%$ tem um rendimento médio e $5,5 \%$ um rendimento alto. $E$, no que concerne à situação face ao trabalho, constituída por dois grupos, a saber: o primeiro "com trabalho", que se refere ao grupo de pessoas que se ocupa diariamente com uma atividade física ou intelectual, que exige esforço e que é realizada para a concretização de um objetivo, ou seja, pessoas que têm um emprego e estudantes (47,3\%); e o segundo grupo, "sem trabalho", que agrupa desempregados e reformados $(52,7 \%)$.

\section{Instrumentos}

No presente trabalho recorremos a dados de três blocos de perguntas do Questionário Necessidades, Interesses e Potencialidades para Desenvolvimento de Programas Intergeracionais (QNIPDPI). Do bloco I - Informações sociodemográficas, utilizámos as seguintes variáveis: idade, sexo, nível de escolaridade, nível socioeconómico, situação face ao emprego. Do bloco II - Participação social, usámos respostas relativas à participação nos espaços e organizações da comunidade, ao voluntariado formal e informal (a ajuda não paga que prestam a outras pessoas por iniciativa própria) e à participação política. Finalmente, do bloco IV - Qualidade de Vida, Saúde e Apoio Social, incluímos as respostas sobre a realização de 15 atividades de lazer.

\section{Procedimento}

A colheita dos dados decorreu entre Março e Maio de 2015, em escolas, centros de formação, centros de dia e de convívio, centros de estudo, lares de terceira idade, associações locais e dois pontos estratégicos à porta da biblioteca Municipal do Porto e à porta da junta de freguesia do Bonfim. Os questionários foram aplicados apenas aos residentes da freguesia. No contacto pessoal e na folha inicial, os participantes foram informados sobre os objetivos do estudo, a confidencialidade dos dados, da voluntariedade da participação e apelou-se à honestidade das respostas. A administração dos questionários foi feita individualmente em três diferentes modalidades, autoadministrado, assistido pelo entrevistador ou administrado pelo entrevistador, sendo esta última forma de administração aplicada sobretudo às pessoas idosas e pessoas com baixos níveis de literacia.

\section{Análise de Dados}

\footnotetext{
${ }^{2}$ Salário médio em Portugal, em 2013, rondava os 963€. GEE/MEE (2013), Boletim estatístico de dezembro de 2013. Disponível em http://www.gee.min-economia.pt [16/01/2016].
} 
De acordo com os objetivos do nosso estudo, na secção seguinte apresentamos os resultados das análises estatísticas que incidiram sobre a amostra total $(n=385)$, e três subamostras etárias, a saber: jovens e adultos jovens com idades compreendidas entre 15 e 44 anos $(n=165)$, adultos de meia-idade, entre 45 e 64 anos $(n=110)$, e adultos idosos com 65 e mais anos $(n=110)$. Calculam-se estatísticas descritivas e inferenciais em função do grupo etário, do sexo, da escolaridade, do nível socioeconómico e da situação face ao emprego, recorrendo-se, para o efeito, a frequências, ao teste qui-quadrado $\left(\mathrm{X}^{2}\right)$, a coeficientes de correlação de Pearson $(r) \mathrm{e}$ Spearman ( $r h o$ ), de acordo com o tipo de respostas e o número de grupos envolvidos. As análises estatísticas foram realizadas recorrendo ao software SPSS, versão 22. Em todas as análises inferenciais foi considerado o nível de significância de 0,05.

\section{Resultados}

\section{Participação formal e informal}

No que diz respeito à participação formal consideramos a participação em atividades de voluntariado. Verifica-se que a participação desta população nas atividades referidas, durante a sua vida é reduzida $(21,3 \%)$, estando a idade significativamente correlacionada com a mesma, embora de magnitude baixa $(r=0,101, p=0,47)$, sendo que à medida que a idade avança a participação diminui (ver tabela 1).

\begin{tabular}{|c|c|c|c|c|c|c|c|c|}
\hline \multirow[b]{3}{*}{ Sim } & \multicolumn{2}{|c|}{$\begin{array}{c}\text { Amostra total } \\
(n=385)\end{array}$} & \multicolumn{2}{|c|}{$\begin{array}{c}\text { Amostra jovens e } \\
\text { adultos jovens } \\
(n=165)\end{array}$} & \multicolumn{2}{|c|}{$\begin{array}{l}\text { Amostra adultos de } \\
\text { meia-idade ( } n=110)\end{array}$} & \multicolumn{2}{|c|}{$\begin{array}{c}\text { Amostra de idosos } \\
(n=110)\end{array}$} \\
\hline & $n$ & $\%$ & $\mathrm{n}$ & $\%$ & $\mathrm{n}$ & $\%$ & $\mathrm{n}$ & $\%$ \\
\hline & 82 & 21,3 & 43 & 26,1 & 21 & 19,1 & 18 & 16,4 \\
\hline Não & 303 & 78,7 & 122 & 73,9 & 89 & 80,9 & 92 & 83,6 \\
\hline
\end{tabular}

Apura-se ainda que a escolaridade está significativamente associada à participação em atividades de voluntariado formal, sendo tanto mais elevada quanto maior é a escolaridade $\left(X^{2}{ }_{(6)}=30,209, p<0,001\right)$, o mesmo se verifica com o nível socioeconómico $\left(x^{2}{ }_{(2)}=17,822, p<0,001\right)$, encontrando-se as pessoas com rendimentos baixos $(43,7 \%)$ e médios $(42,3 \%)$ como aquelas que fazem mais voluntariado. No respeitante à situação face ao trabalho $\left(X^{2}{ }_{(1)}=5,303, p=0,021\right)$, são as pessoas sem trabalho quem realiza mais atividades de voluntariado formal. A participação neste tipo de atividades, não se encontra relacionada com o sexo $\left(x^{2}{ }_{(1)}=0,218, p=0,640\right)$.

As atividades de voluntariado mais praticadas são as de caridade $(9,6 \%)$, as relacionadas com organizações religiosas $(7,5 \%)$, com associações desportivas e recreativas $(4,9 \%)$, tendo as restantes atividades uma representação menor do que $2 \%$, a saber, por ordem decrescente: artísticas e de passatempos $(1,8 \%)$; outras atividades - indicadas pelos inquiridos, em centro de dia e de convívio, bombeiros voluntários, colónias de férias e associações de pais - $(1,6 \%)$; ambientais ou cuidado de animais $(1,6 \%)$; grupos musicais $(1,3 \%)$; organizações políticas $(1 \%)$; serviços de saúde $(1 \%)$ e organizações de defesa dos direitos humanos $(0,3 \%)$.

No que concerne à participação informal, analisámos a ajuda não paga prestada por iniciativa própria a outras pessoas (voluntariado informal - ajuda e apoio). Verifica-se que um pouco mais de metade da população estudada presta este tipo de ajuda $(55,1 \%)$, e que esta variável não está relacionada com a idade $(r=-0,058, p=0,255)$, a escolaridade $\left(x_{(6)}^{2}=4,357, p=0,629\right)$, o nível socioeconómico $\left(x_{(6)}^{2}=4,258, p=0,119\right)$, nem com a situação face ao trabalho $\left(X^{2}{ }_{(1)}=2,194, p=0,139\right)$. 
O tipo de voluntariado informal (ajuda e apoio) mais prestado é ouvir as pessoas $(52,7 \%)$, seguido da ajuda nas compras $(42,5 \%)$, tomar conta de crianças $(31,9 \%)$, ajudar na alimentação e a cozinhar $(23,7 \%)$, apoiar na realização dos trabalhos escolares $(21,3 \%)$ (ver tabela 2 ). Presta-se mais ajuda e apoio maioritariamente a familiares (54\%), seguidos dos amigos (26\%) e por último aos vizinhos $(20 \%)$. O apoio mais prestado à família é: ajuda nas compras (34,7\%), ouvir as pessoas $(32,4 \%)$, tomar conta das crianças $(24,7 \%)$, apoio nos trabalhos escolares $(20 \%)$, ajuda na alimentação e a cozinhar (15,8\%). No caso dos amigos, por ordem decrescente, surgem as seguintes ajudas: ouvir as pessoas (35,6\%), ajuda nos trabalhos de manutenção da casa $(10,5 \%)$, tomar conta de crianças $(8,4 \%)$ e ajuda na alimentação e a cozinhar $(7,4 \%)$. E no caso dos vizinhos verificou-se a seguinte ordem: ouvir as pessoas $(19,7 \%)$, ajuda nas compras $(8,9 \%)$, apoio nos trabalhos de manutenção da casa $(7,9 \%)$, ajuda na alimentação e a cozinhar $(4,7 \%)$ (ver tabela 2$)$.

\begin{tabular}{|lcccc|}
\hline \multicolumn{5}{|c|}{ Tabela 2: Participação em voluntariado informal (ajuda e apoio) da amostra total, por tipo e (\%) } \\
\hline Tipo de voluntariado informal & Sim & Familiares & Amigos & Vizinhos \\
\hline Ouve as pessoas & 52,7 & 32,4 & 35,6 & 19,7 \\
Ajuda nas compras & 42,5 & 34,7 & 4,2 & 8,9 \\
Toma conta das crianças & 31,9 & 24,7 & 8,4 & 2,1 \\
Ajuda na alimentação e a cozinhar & 23,7 & 15,8 & 7,4 & 4,7 \\
Ajuda na realização dos trabalhos escolares & 21,3 & 20 & 4,2 & 2,1 \\
Ajuda em trabalhos de manutenção da casa & 19,8 & 9,5 & 10,5 & 7,9 \\
Ajuda na toma da medicação & 12,6 & 9,5 & 0,5 & 2,6 \\
Ajuda no jardim ou quintal & 11,6 & 4,8 & 3,2 & 4,2 \\
Ajuda em transporte & 10,6 & 6,8 & 3,7 & 3,2 \\
Ajuda em cuidados de higiene & 10,6 & 6,8 & 1,1 & 1,6 \\
Outras & 6,3 & 3,2 & 2,6 & 5,3 \\
\hline
\end{tabular}

Embora o sexo não esteja estatisticamente associado à participação informal $\left(X^{2}{ }_{(1)}=1,011, p=0,315\right)$, verifica-se que as ajudas prestadas por homens e mulheres estão relacionadas com a divisão do trabalho doméstico entre os sexos. Assim, e utilizando a tipologia das tarefas domésticas proposta por Bernard Zarca (1990), ou seja, tarefas femininas (executadas maioritariamente por mulheres), tarefas masculinas (executadas maioritariamente por homens) e tarefas negociáveis (tarefas realizadas sobretudo por mulheres, mas nas quais os homens também participam), verifica-se que as mulheres do nosso estudo ajudam outras pessoas maioritariamente nas tarefas femininas: ouvir $(34,1 \%)$; tomar conta de crianças $(17,5 \%)$; ajudar na alimentação e a cozinhar (17,5\%); ajudar na toma de medicação $(8,3 \%)$; apoiar nos cuidados de higiene $(7,8 \%)$. Em contrapartida, os homens prestam ajuda maioritariamente nas tarefas masculinas: ajuda em trabalhos de manutenção da casa $(17,2 \%)$ e no cuidado ao jardim ou quintal $(7,4 \%)$. No que respeita a atividades com percentagens mais aproximadas entre homens e mulheres, as designadas tarefas negociáveis, registam-se a ajuda nas compras (25,3\% das mulheres e $20,2 \%$ dos homens), e na realização dos trabalhos escolares (12\% mulheres e $11 \%$ os homens). Os dados emergentes demonstram uma clara divisão das ajudas prestadas por homens e mulheres na freguesia em estudo, resultante dos papéis de género atribuídos socialmente a homens e mulheres.

\section{Participação política}

No que diz respeito ao interesse pela política, $34,3 \%$ da população afirma não ter qualquer interesse, $27 \%$ refere pouco interesse, $28,3 \%$ algum interesse e $10,1 \%$ muito interesse. Verifica-se que a idade não está significativamente correlacionada com o interesse pela política $(r=0,28, p=0,585)$, mas que existe uma correlação significativa no caso da escolaridade $(r h o=0,234 p<0,001)$, do nível socioeconómico ( $r h o=0,206$, 
$p<0,001)$ e a situação face ao emprego $\left(x^{2}{ }_{(3)}=11,350, p=0,010\right)$, sendo que quanto maior o nível educativo e os rendimentos, maior é o interesse pela política e são as pessoas sem trabalho quem tem menos interesse pela política. Apura-se, ainda, que 0 sexo está significativamente associado ao interesse pela política $\left(X_{(3)}^{2}=11,100\right.$, $p=0,011)$, sendo os homens que demonstram mais interesse.

Os dados anteriores indicam um desinteresse pela política por parte da população estudada, contudo, verifica-se que a maioria das pessoas vota sempre $(52,7 \%)$. A idade está significativamente correlacionada com a frequência de voto $(r=0,288$, $p<0,001$ ), sendo os idosos quem vota com mais frequência e os jovens e adultos jovens quem menos vota. A frequência de voto não está correlacionada significativamente com o sexo $\left(x^{2}(3)=4,494, p=0,213\right)$, nem com o nível de escolaridade $(r h o=0,061, p=0,235)$ e a situação face ao trabalho $\left(x_{(3)}^{2}=7,459, p=0,059\right)$, mas está correlacionada com o nível socioeconómico $(r h o=0,116, p=0,035)$, sendo as pessoas com rendimentos mais elevados quem vota com mais frequência.

Da análise da participação da população em outras ações políticas, verifica-se que as mais realizadas são, por ordem decrescente: manifestações (27,7\%); greves (18,6\%); debates e reuniões (14,1\%); participação em assembleias ou reuniões de sindicatos, associações recreativas de estudantes ou profissionais $(10,5 \%)$; participação em assembleias da freguesia ou municipal $(9,2 \%)$; colar cartazes $(6,8 \%)$; participação na Assembleia da República $(1,8 \%)$ e, por último, em ações violentas $(0,8 \%)$. E apura-se que $54,5 \%$ da amostra global nunca participou em nenhuma destas ações políticas. A idade não está significativamente correlacionada com estes resultados $(r=0,90$, $p=0,78$ ), contudo, verifica-se que são os adultos idosos quem menos realizou diferentes tipos de ações políticas $(65,5 \%)$, seguidos dos jovens e adultos jovens $(53,1 \%)$ e dos adultos de meia-idade $(45,5 \%)$. O nível socioeconómico não está estatisticamente correlacionado com a participação em outras ações políticas ( $r h o=0,078, p=0,155)$, nem o sexo $\left(x_{(1)}^{2}=0,796, p=0,372\right)$, contudo, encontra-se uma correlação significativa com a escolaridade $(r h o=0,201, p<0,001)$, e com a situação face ao trabalho $\left(X^{2}{ }_{(1)}=0,796, p=0,372\right)$, sendo as pessoas "sem trabalho" as que mais participam em outro tipo de ações políticas e que a participação aumenta à medida que o nível de escolaridade aumenta.

\section{Participação em organizações e instituições locais}

Analisando a participação social tendo em conta as organizações e instituições que as pessoas frequentaram ou frequentam, e considerando que a mesma pessoa frequentou ao longo da vida diferentes organizações e instituições, verifica-se que são as associações que registam a maior percentagem de participação $(17,6 \%)$; seguidas pelos centros de dia $(13,6 \%)$; os centros de convívio $(12 \%)$; centros de cultura e desporto $(10,6 \%)$; outras - os inquiridos indicaram lares, congregações religiosas, sedes de partido e Centros de Novas Oportunidades - (8\%); centros de atividades dos tempos livres - ATL (5,9\%); centros de estudo e explicações (4\%); centros de férias e lazer $(4 \%)$; centros comunitários $(3,7 \%)$; centros de atividades ocupacionais - CAO $(3,5 \%)$; centros de atendimento/acompanhamento e animação para pessoas com deficiência $(1,3 \%)$; universidade sénior $(1,1 \%)$ e fóruns ocupacionais $(0,8 \%)$.

Analisando a frequência de organizações e instituições por grupo etário, verifica-se que a frequência no grupo dos jovens e adultos jovens é de $41,9 \%$; no grupo dos adultos de meia-idade de $34,3 \%$ e no grupo das pessoas idosas de $66,7 \%$. Os jovens frequentam ou frequentaram maioritariamente, centros de estudo e explicações (93,3\%); ATL (72,7\%); associações (54,4\%); CAO (53,8\%); centros de cultura e desporto (52,5\%); centros de férias e lazer (40\%). Os adultos de meia-idade obtêm a 
mesma percentagem de frequência que os idosos nos centros comunitários (42,9\%), não estando maioritariamente representados em nenhuma outra organização ou instituição. E os idosos frequentam ou frequentaram, maioritariamente, centros de dia $(86,3 \%)$ e centros de convívio $(77,8 \%)$. No que diz respeito ao sexo, elas estão maioritariamente nos centros de dia $(78,4 \%)$ e nos centros de convívio $(71,1 \%)$ e eles estão em maioria nas associações $(65,2 \%)$ e nos centros de cultura e desporto $(70 \%)$. No que concerne à escolaridade, as pessoas sem escolaridade são quem mais frequentam ou frequentaram estes espaços $(28 \%)$, seguidas das pessoas com o $2^{\circ}$ ciclo $(18 \%)$; $1^{\circ}$ ciclo $(16 \%)$; ensino superior $(14 \%)$; $3^{\circ}$ ciclo $(12 \%)$ e secundário $(12 \%)$. As pessoas sem níveis de estudos são quem frequentaram ou frequentam em maior percentagem a maioria das instituições e organizações, com exceção das associações e dos centros de cultura e desporto que são ou foram frequentadas maioritariamente por pessoas com ensino superior e dos centros de férias e lazer que são ou foram frequentados maioritariamente por pessoas com o $2^{\circ}$ ciclo. Apura-se ainda que, à medida que os rendimentos aumentam a participação nas organizações e instituições da comunidade diminui, sendo que $49 \%$ das pessoas que frequentam ou frequentaram estas organizações e instituições têm baixos rendimentos, $34,2 \%$ têm rendimentos médios e $6,6 \%$ são pessoas com rendimentos elevados. No que concerne à situação face ao trabalho (aqui analisada pelos seguintes grupos, estudantes, reformados, empregados e desempregados), verifica-se que são os estudantes que mais frequentam ou frequentaram estas organizações e intuições (35\%), estando representados maioritariamente nas associações $(34,2 \%)$, nos ATL $(18,4 \%)$, nos centros de estudos ou explicações $(18,4 \%)$ e em centros de férias e lazer $(7,9 \%)$. Seguem-se os reformados (34\%), que estão maioritariamente representados nos centros de dia $(29,1 \%)$; nos centros de convívio $(36,2 \%)$; em outros tipos de organizações e instituições $(13,4 \%)$ e nos centros comunitários $(6,3 \%)$. As pessoas empregadas $(16 \%)$ estão maioritariamente representadas nos centros de cultura e desporto $(4,3 \%)$ e nos centros de atividades ocupacionais (4,3\%). E, finalmente, em relação aos desempregados (15\%), constata-se que não frequentam ou frequentaram maioritariamente nenhuma organização ou instituição.

\section{Atividades}

$\mathrm{Na}$ análise de atividades de lazer, atividades muito variadas, realizadas no tempo livre mas que implicam certa atividade física e/ou mental, utilizámos a categorização atividades fora de casa e atividades dentro de casa (CABRAL et al., 2013). Assim, quanto às primeiras definiram-se as seguintes: jardinagem e horta; estar com amigos; atividades religiosas; atividades fora de casa como ir ao cinema, visitar uma exposição, jantar fora; fazer exercício físico; voluntariado e viajar. Estas atividades pressupõem um determinado nível de atividade física e apontam, igualmente, para um nível diferente de envolvimento e participação social. Como atividades dentro de casa, atividades que são consideradas fisicamente mais passivas e frequentemente praticadas individualmente, definimos: ver televisão; estar com a família; ouvir música; ler; atividades sociais na internet; costura e tricot; colecionismo e atividades artísticas ${ }^{3}$.

Sendo o nosso objetivo compreender quais as atividades de lazer mais praticadas pela nossa população e se são atividades mais ativas ou passivas, usamos apenas as respostas frequentemente e todos os dias da escala de Likert utilizada (que varia entre nunca e todos os dias). Assim, verifica-se que $64 \%$ das atividades realizadas por esta

\footnotetext{
${ }^{3}$ Esta categorização é passível de discussão, visto que muitas destas atividades podem ser realizadas dentro ou fora de casa, realizadas individualmente ou com o envolvimento de outras pessoas e ainda serem consideradas ativas ou passivas. Contudo, depois de pesquisarmos vários estudos sobre as atividades de lazer, e de encontrarmos uma grande diversidade de categorizações das atividades de lazer, optámos por esta categorização por estar mais de acordo como os nossos objetivos.
} 
população situam-se na esfera dentro de casa e $36 \%$ na esfera das atividades fora de casa. Na primeira esfera, as atividades praticadas com mais frequência são ver televisão $(73 \%)$, estar com a família $(71,9 \%)$, ouvir música $(66,5 \%)$ e ler $(37,9 \%)$; na segunda, as atividades mais praticadas são: estar com os amigos (67,3\%); fazer exercício físico $(30,9 \%)$; ir ao cinema, visitar uma exposição, jantar fora $(24,9 \%)$ e atividades religiosas $(20 \%)$ (ver tabela 3$)$.

\begin{tabular}{|c|c|c|c|c|}
\hline \multirow[t]{2}{*}{ Atividades } & \multicolumn{4}{|c|}{ Amostras } \\
\hline & $\begin{array}{c}\text { Amostra total } \\
(n=381)\end{array}$ & $\begin{array}{l}\text { Jovens e adultos } \\
\text { jovens ( } n=162)\end{array}$ & $\begin{array}{c}\text { Adultos de meia } \\
\text { idade }(n=110)\end{array}$ & Idosos $(n=109)$ \\
\hline \multicolumn{5}{|l|}{ DENTRO DE CASA } \\
\hline Ver televisão & 73 & 67,3 & 79,1 & 75,5 \\
\hline Estar com a família & 71,9 & 77,6 & 78,2 & 57,3 \\
\hline Ouvir música & 66,5 & 80 & 67,3 & 45,5 \\
\hline Ler & 37,9 & 40,6 & 40 & 31,8 \\
\hline Atividades sociais na internet & 19,2 & 35,2 & 13,6 & 0,9 \\
\hline Atividades artísticas & 10,6 & 18,8 & 4,5 & 4,5 \\
\hline Costura e tricot & 6 & 1,8 & 7,3 & 10,9 \\
\hline Colecionismo & 3,4 & 3 & 6,4 & 0,9 \\
\hline \multicolumn{5}{|l|}{ FORA DE CASA } \\
\hline Estar com os amigos & 67,3 & 74,5 & 63,6 & 60 \\
\hline Fazer exercício físico & 30,9 & 39,4 & 28,2 & 20,9 \\
\hline Atividades fora de casa & 24,9 & 41,5 & 15,5 & 10 \\
\hline Atividades religiosas & 20,5 & 16,4 & 20 & 27,3 \\
\hline Voluntariado & 8,1 & 7,9 & 8,2 & 8,2 \\
\hline Jardinagem e horta & 6,8 & 4,2 & 11,8 & 5,5 \\
\hline Viajar & 6 & 6,7 & 6,4 & 4,6 \\
\hline
\end{tabular}

Como se pode ver na tabela 3 , à medida que a idade avança a participação nas atividades quer dentro, quer fora de casa diminui. Com exceção de algumas atividades como ver televisão, fazer costura e tricot e as atividades religiosas, sendo que estas últimas aumentam com a idade. De salientar ainda que a atividade de ver televisão é realizada com maior frequência pelos adultos de meia-idade.

Analisando a atividade por sexo, verifica-se que são os homens que praticam mais atividades de lazer, superando as mulheres em 12 das 15 atividades analisadas. As únicas atividades em que elas obtêm maiores percentagens são as atividades religiosas $(24,8 \%)$, a costura e o tricot $(10,1 \%)$ e a jardinagem e horta $(8,3 \%)$. Nas mesmas atividades eles pontuam $15,3 \%, 0,6 \%$ e 4,9\%, respetivamente.

Apura-se que à medida que a escolaridade aumenta, a participação nas atividades de lazer também aumenta, quer dentro de casa [sem nível educativo (12\%); $1^{\circ}$ ciclo (13\%); $2^{\circ}$ ciclo (17\%); $3^{\circ}$ ciclo (18\%); secundário (19\%), e ensino superior $\left.(21 \%)\right]$, quer fora de casa [sem nível educativo (12\%); $1^{\circ}$ ciclo (13\%); $2^{\circ}$ ciclo $(15 \%) ; 3^{\circ}$ ciclo $(16 \%)$; secundário (21\%), e ensino superior (23\%)]. As pessoas com níveis educativos de ensino secundário e ensino superior são as que mais realizam as seguintes atividades: estar com a família $(87,7 \%$ e $78,4 \%)$, estar com amigos $(82,2 \%$ e $81,1 \%)$, ouvir música $(83,6 \%$ e $83,8 \%)$, ler $(41,1 \%$ e $71,6 \%)$, realizar atividades artísticas $(13,7 \%$ e $25,7 \%)$, voluntariado $(9,6 \%$ e $17,6 \%)$ e atividades fora de casa, como ir ao cinema, visitar uma exposição, jantar fora, etc. (37\% e 44,6\%). As pessoas de níveis de escolaridade intermédios ( $2^{\circ}$ e $3^{\circ}$ ciclos) são as que mais veem televisão ( $85 \%$ e $80 \%$ ), as que mais colecionam $(5 \%$ e $6,2 \%)$ e as que menos realizam atividades religiosas $(10 \%$ e $12,3 \%$ ). As pessoas com os mais baixos níveis educativos, sem qualquer grau de 
instrução e $1^{\circ}$ ciclo, são as que realizam com mais frequência a atividade de costura e tricot $(4,2 \%$ e $13,5 \%)$ e a jardinagem e cuidado da horta $(16,7 \%$ e $5,8 \%)$.

Segundo o nível socioeconómico, o grupo das pessoas com rendimentos mais elevados é quem mais se envolve em atividades de lazer, em 11 das 15 atividades analisadas, a saber: ver televisão $(90,5 \%)$, ouvir música $(85,7 \%)$; estar com a família $(76,2 \%)$; estar com os amigos $(76,2 \%)$; fazer exercício físico $(33,3 \%)$; voluntariado $(28,6 \%)$; atividades fora de casa $(28,6 \%)$; viajar $(23,8 \%)$; atividades na internet $(12,9 \%)$; e jardinagem e horta $(9,5 \%)$. O grupo das pessoas com rendimentos médios realizam com mais frequência apenas uma atividade, ler (46,6\%). Por sua vez, o grupo com baixos rendimentos, realiza com mais frequência atividades religiosas $(22,1 \%)$, costura e tricot $(7,2 \%)$ e colecionismo $(4,3 \%)$. As atividades religiosas são aquelas em que se encontra uma percentagem de frequência mais aproximada entre as pessoas dos diferentes níveis socioeconómicos, $22,1 \%$ no grupo das pessoas com baixos rendimentos, $21,8 \%$ no grupo das pessoas de rendimentos médios e $19 \%$ no grupo das pessoas com rendimentos elevados.

Finalmente, verifica-se que as pessoas "com trabalho" praticam um pouco mais de atividades de lazer do que aquelas "sem trabalho", quer dentro de casa (56\%, 44\%), quer fora de casa $(55 \%, 45 \%)$, respetivamente, sendo que as pessoas "com trabalho" praticam com mais frequência as seguintes atividades, por ordem decrescente: estar com a família (82,9\%); ouvir música $(77,3 \%)$; estar com os amigos $(76,2 \%)$; ler $(44,2 \%)$; fazer exercício físico (36,5\%); atividades fora de casa, como ir ao cinema, visitar uma exposição, jantar fora, etc. (34,3\%); atividades sociais na internet $(30,4 \%)$ e atividades artísticas (16\%). E as pessoas "sem trabalho" dedicam-se maioritariamente a ver televisão (77\%); a atividades religiosas (21,5\%); a jardinagem e horta $(9,5 \%)$ e a costura e tricot $(8,5 \%)$. As atividades com percentagens mais aproximadas entre estes dois grupos são: voluntariado $(8,3 \%, 8 \%)$; viajar $(6,1 \%, 6 \%)$ e colecionismo $(3,3 \%$, $3,5 \%)$, respetivamente.

\section{Discussão}

Em primeiro lugar, há que salientar que os resultados obtidos neste estudo demonstram que a atividade da amostra estudada é baixa. No que diz respeito à participação na sociedade, participação em atividades de voluntariado e participação política, verificou-se uma participação média-baixa, resultados idênticos aos encontrados nos estudos do Active Ageing Índex 2014 (UNECE, 2015), para a população portuguesa. Mais especificamente, a participação em atividades de voluntariado formal, pelo menos uma vez na vida, é baixa $(21,3 \%)$, a participação no voluntariado informal (ajuda prestada a outras pessoas) é média $(55,1 \%)$ e a participação política é baixa, visto que apenas metade da população vota sempre $(52,7 \%)$ e $54,5 \%$ nunca participou em nenhuma outra ação política durante toda a sua vida. Verificou-se um desinteresse geral pela política, que ascende a $34,3 \%$ (não ter qualquer interesse), sendo que apenas $10,1 \%$ refere ter muito interesse, mais uma vez resultados idênticos aos do estudo dos 28 estados membros da União Europeia, Active Ageing Índex 2014 (UNECE, 2015), em que Portugal ficou em segundo lugar no ranking do país que afirma não ter nenhum interesse $(28 \%)$ e em último lugar entre os que afirmam ter "muito interesse" pela política $(6 \%)$.

No que concerne às atividades de lazer, apurou-se que as atividades que se praticam com maior frequência são aquelas que ocorrem dentro de casa, chegando quase a duplicar a frequência das atividades fora de casa, $64 \%$ e $36 \%$, respetivamente, o que significa que dedicam mais tempo a atividades fisicamente mais passivas $e$ 
frequentemente praticadas de forma individual do que a atividades que exigem mais atividade física e maior envolvimento e participação social.

Em segundo lugar, querendo compreender se a atividade difere de geração para geração, verificou-se que à medida que a idade avança a participação em atividades de voluntariado formal diminui, resultados idênticos foram encontrados no Inquérito nacional ao trabalho voluntário (INE, 2013). Possíveis explicações para estes resultados são as mudanças do estado de saúde e mental à medida que a idade avança, mas também o aumento de investimento político em atividades de voluntariado nas últimas décadas, dirigidas sobretudo às gerações mais jovens e não tanto às gerações mais velhas. No que concerne ao voluntariado informal, não se registaram diferenças significativas entre as gerações, demonstrando, por um lado, que existe solidariedade entre as pessoas na comunidade estudada e, por outro lado, que esta solidariedade é intergeracional. Apurou-se, igualmente, uma diferença entre as gerações, no que concerne à frequência de voto, verificando-se que neste caso, à medida que a idade aumenta a frequência de voto aumenta também. Resultados semelhantes têm sido encontrados na literatura (Blais, 2000; Franklin, 2004), sendo que a explicação para a tendência dos jovens votarem menos é a de que a propensão vai aumentando com a idade (Plutzer, 2002; Franklin, 2004), com a formação do hábito de participar nas decisões da sociedade (Plutzer, 2002) e com o desenvolvimento de um maior entendimento sobre as diferenças partidárias e sobre os assuntos socioeconómicos. A este respeito, Martins (2010) salienta que o facto das redes sociais dos jovens serem constituídas principalmente por pares, também eles com pouco conhecimento sobre a política, contribui para que este grupo etário vote menos. Contudo, importa referir que no que diz respeito ao interesse pela política não se encontraram diferenças estatisticamente significativas entre as diferentes gerações. No que diz respeito às atividades de lazer, verifica-se que à medida que a idade aumenta a prática da maioria destas atividades passa a ser menor, com a exceção de ver televisão, fazer costura e tricot e das atividades religiosas. Encontra-se, porém, uma semelhança nas percentagens obtidas nas frequências das atividades, ou seja, embora as percentagens de frequência difiram entre os grupos etários, o perfil das atividades que praticam mais e das que praticam menos é muito semelhante. Consideramos este dado muito relevante, visto que em dois estudos longitudinais sobre as atividades de lazer, um realizado na Holanda, por Aartsen, Smits, Tilburg, Knipscheer e Deeg (2002) que seguiram durante 6 anos, 2076 pessoas entre os 55-85 anos de idade, e outro levado a efeito na Suíça, por Agahi, Ahacic e Parker (2006), que seguiram durante 34 anos 495 indivíduos com idades compreendidas entre os 4365 anos, em 1968, e os 77-99, anos em 2002, mostraram que as atividades mais frequentes na avaliação inicial eram as mesmas nas avaliações posteriores e, por isso, concluíram que as atividades realizadas na velhice são influenciadas por participação prévia, durante a fase adulta, o que sugere que as pessoas das gerações mais novas da nossa amostra quando alcançarem 65 e mais anos continuarão a realizar atividades mais passivas e frequentemente praticadas de forma individual. Ora, sendo o objetivo do envelhecimento ativo a promoção da participação dos adultos idosos em atividades mais ativas e que impliquem maior envolvimento e participação social, favorecedores da saúde, qualidade de vida e do bem-estar na velhice, torna-se assim fundamental oferecer oportunidades e educar as gerações mais novas para alterarem este padrão.

Em terceiro lugar, da análise das restantes características sociodemográficas, encontrámos como fatores de relevo em termos do envelhecimento ativo, o sexo, o nível de escolaridade e o nível socioeconómico. Constatámos também que a situação face ao trabalho não parece influenciar tanto a atividade destes indivíduos. Assim, no que diz respeito ao sexo, verificou-se que não existem diferenças significativas na participação de homens e mulheres em voluntariado formal, informal e frequência de 
voto, mas que existem diferenças no que concerne ao interesse pela política e na realização de atividades de lazer. Resultados semelhantes foram encontrados no relatório Gender Equality Index 2015 (EIGE, 2015), para Portugal, sendo os homens quem mais demonstra ter interesse por este assunto e quem realiza mais atividades de lazer. Estes resultados confirmam igualmente os resultados de investigações apresentados por Argyle (1996), em relação ao lazer, os quais salientam que a quantidade total de lazer e o tipo de lazer diferem entre homens e mulheres. Dos dados obtidos neste estudo, apurou-se que a participação de homens e mulheres está condicionada aos papéis de género. Assim, no voluntariado informal verificou-se que as ajudas prestadas por homens e mulheres estão relacionadas com a divisão do trabalho doméstico entre os sexos (Zarca, 1990), são eles que frequentam mais atividades de lazer, o que se explica por terem mais tempo livre do que as mulheres, uma vez que dedicam menos tempo à esfera familiar do que elas (EIGE, 2015; Torres, Silva, Monteiro \& Cabrita, 2005). Verificou-se também que são os homens quem tem mais interesse pela política, sendo este domínio, por excelência, um campo simbólico do poder que continua a ser um reduto da dominação masculina, alicerçado em valores e normas masculinos, e apresentando grandes resistências à participação feminina (Maciel, 2008; EIGE, 2015). No que concerne à escolaridade, quanto mais elevado o seu nível, mais elevada é a participação em atividades de voluntariado formal, maior a frequência da prática de atividades de lazer e maior é o interesse pela política, não se verificando, contudo, diferenças significativas entre a escolaridade e a frequência de voto, nem na prática de voluntariado informal. Considerando o nível socioeconómico, verificou-se que são as pessoas com os rendimentos mais elevados quem mais vota, quem demonstra ter maior interesse pela política e quem pratica com maior frequência as atividades de lazer analisadas. No que diz respeito ao voluntariado informal não se encontraram diferenças significativas entre os rendimentos e quem participa nestas atividades, mas no voluntariado formal sim, sendo as pessoas com rendimentos mais baixos quem participa mais neste tipo de atividade. Quanto à situação face ao trabalho, verificou-se ao nível da participação que são as pessoas "sem trabalho" (reformados e desempregados) que participam mais em atividades de voluntariado formal e aquelas que mais utilizam ações políticas que não o voto. $E$ no que diz respeito às atividades de lazer, verificou-se que as percentagens entre as pessoas "com trabalho" e as pessoas "sem trabalho", são muito aproximadas, são contudo, pessoas "com trabalho" que apresentam uma percentagem superior na realização de atividades, quer fora de casa, quer nas atividades dentro de casa.

Por último, sendo que o objetivo deste estudo é o de contribuir para promover o desenvolvimento de programas educativos intergeracionais na comunidade, interessava-nos compreender qual a participação da população nas organizações e instituições locais. Tendo em consideração que a recolha de dados foi realizada em muitas das instituições e organizações da comunidade, os $46,8 \%$ da população em estudo que afirma frequentar ou ter frequentado, pelo menos uma instituição ou organização, durante a sua vida, é uma percentagem muito baixa. As pessoas dos extremos do ciclo vital são quem mais frequentam ou frequentaram estes espaços, $66,7 \%$ do grupo dos adultos idosos e $41,9 \%$ do grupo dos jovens e que verifica-se, que as respostas sociais dirigidas à comunidade, tais como, os centros comunitários, centros de férias e lazer, centros de cultura e desporto, associações, correspondem aos espaços onde se encontra a maior heterogeneidade de idades entre as pessoas.

\section{Conclusão}

De acordo com os resultados obtidos, conclui-se, por um lado, que esta população tem uma participação na sociedade média-baixa e que as atividades de lazer realizadas com mais frequência são atividades fisicamente mais passivas e frequentemente 
praticadas de modo individual. Por outro lado, evidenciou-se que características sociodemográficas tais como a idade, o sexo, a escolaridade e os rendimentos dos indivíduos estão estreitamente relacionadas com a atividade das pessoas, quer na participação na sociedade, quer nas atividades de lazer, desenhando-se o perfil de que as pessoas mais ativas são os homens, as que têm maiores níveis de escolaridade e maiores rendimentos. Verificou-se igualmente, que as pessoas estão ocupadas diariamente com uma atividade física ou intelectual, que exige esforço e que é realizada para a concretização de um objetivo, estudantes e empregados, são mais ativas do que as pessoas desempregadas e os reformados, dedicando mais tempo a atividades de lazer quer dentro e quer fora de casa.

Importa aqui referir que, se por um lado concordamos que o aumento da escolaridade, de melhores condições de vida e da igualdade entre os géneros que se regista nas nossas sociedades resultará no futuro num aumento do envelhecimento ativo e saudável de indivíduos e populações (Cabral, Ferreira, Alcântara, Jerónimo \& Marques, 2013), por outro lado, atendendo a que as desigualdades sociais estão a aumentar nas sociedades desenvolvidas contemporâneas, esta tendência dará origem a trajetórias de envelhecimento de indivíduos e populações bastante diferentes. Por outras palavras, o envelhecimento ativo não será a realidade de todos os indivíduos e populações, pelo que se torna necessário encontrar estratégias efetivas para promover o envelhecimento ativo, digno e saudável de todos os indivíduos. Muitas das respostas sociais do Estado e organizações civis procuram dar oportunidades de atividade, ocupação de tempos livre e inclusão a indivíduos mais marginalizados, todavia, concluímos do nosso estudo que, embora estas instituições contribuam para o aumento da participação e a atividade dos seus usuários a participação nestes espaços é baixa. Por outro lado, porque as respostas sociais são dirigidas a gruposalvos específicos, quase sempre selecionados por idades, verifica-se que estas respostas apartam gerações, desaproveitando oportunidades, visto que a literatura confirma que as relações, atividades e programas intergeracionais contribuem para a promoção do envelhecimento ativo e o envolvimento de diferentes gerações em atividades individual e socialmente muito úteis (Maccallum et al, 2010; Pinazo \& Kaplan, 2007; Sánchez, Díaz, López, Pinazo e Sáez, 2008). Por último, constata-se que a freguesia aqui estudada apresenta grandes potencialidades para a promoção do envelhecimento ativo, porque no seu território se localizam várias instituições e organizações que podem ser utilizadas como recursos societais de grande relevância. Importa mencionar que se estas organizações e instituições estabelecerem iniciativas de parceria para colocarem em prática a educação intergeracional, o custo económico do desenvolvimento destas atividades e programas é irrisório. Mais ainda, tendo em conta os resultados positivos que podem alcançar para a comunidade do Bonfim, apresentam-se como um benefício que de modo algum pode ser desconsiderado.

E finalmente, para fomentar o envelhecimento ativo de indivíduos e populações é necessário não só criar oportunidades para os adultos idosos, mas também para as gerações de jovens, jovens adultos e adultos de meia-idade, já que, por um lado, se apurou que a participação de todas as faixas etárias é média-baixa e, por outro lado, que existe um perfil das atividades realizadas com mais ou menos frequência muito idêntico entre as gerações, ou seja, as atividades de lazer realizadas com mais frequência pelos nossos jovens são as mesmas, embora em percentagens diferentes, das gerações mais antigas/mais velhas. Assim, se estes jovens mantiverem os mesmos hábitos durante a sua vida, quando alcançarem os 65 e mais anos realizarão com mais frequência as atividades fisicamente mais passivas e frequentemente praticadas de forma individual (Aartsen et al., 2002; Agahi et al., 2009). Deste modo, é fundamental quebrar este ciclo tendencioso e promover atividades de qualidade e saudáveis nos indivíduos desde a mais tenra idade, já que o que se pretende com o 
paradigma de envelhecimento ativo é criar um novo modelo de sociedade, que resultará num novo habitus da velhice e do envelhecimento.

Das conclusões supramencionadas com base na nossa amostra, conclui-se que é necessário oferecer oportunidades de participação, aumentar o lazer, as atividades físicas e cognitivas e o contacto social destes indivíduos, de forma a promover o envelhecimento ativo e a qualidade de vida desta população. As atividades de lazer apresentam-se como promotoras de desenvolvimento pessoal, social e de bem-estar, assegurando múltiplas funções sociais, psicológicas e de saúde (Coleman \& IssoAhole, 1993; Argyle, 1996). Tal como referimos anteriormente, a educação intergeracional é uma estratégia com grande potencial para atingir estes objetivos. Assim, o desenvolvimento de atividades, projetos e programas intergeracionais, através dos quais a educação intergeracional é colocada em prática, é pertinente não só para o grupo de pessoas da nossa amostra, mas também para toda a comunidade local, bem como para a sociedade portuguesa, visto que encontrámos, a nível local, muitos resultados idênticos aos já evidenciados por estudos prévios relativos a todo 0 país, entre os quais o facto da atividade dos adultos idosos portugueses ser baixa, relativamente aos 28 Estados membros da União Europeia (UNECE, 2015).

Referências

Aartsen, M., Smits, C., Tilburg, T.V., Knipscheer, K., \& Deeg, D. (2002). Activity in older adults: cause or consequences of cognitive functioning? A longitudinal study on everyday activities and cognitive performance in older adults. $J$ gerontol B Psychol Sci Soc Sic., 57(2), 153-162.

Agahi, N., Ahacic, K., \& Parker, M. (2006). Continuity of leisure participation from middle age to old age. J Gerontol B Psychol Sci Soc Sci, 61(6), S340-346.

Argyle, M. (1996). The social psychology of leisure. London: Penguim Books.

Blais, A. (2000). To Vote or Not to Vote: The merits and Limits of Rational Choice Theory. Pittsburgh: University of Pittsburgh Press.

Cabral, M., Ferreira, P., Alcântara, P., Jerónimo, P., \& Marques, T. (2013). Envelhecimento ativo em Portugal: Trabalho, reforma, lazer e redes sociais. Lisboa: Fundação Francisco Manuel dos Santos.

Coleman, D. \& Isso-Ahola, S. (1993). Leisure and health: the role of social support and self- determination. Journal of Leisure Research, 25, 111-12.

EUROPEAN INSTITUTE FOR GENDER EQUALITY. Gender Equality Index 2015: Measuring gender equality in the European Union 2005-2012. Recuperado de Acedido http://eige.europa.eu. http://www.webcitation.org/6oaWSQSLI

Franklin, M. (2004). Voter Turnout and the Dynamics of Electoral Competition in Established Democracies Since 1945. NY: Cambridge University Press

INSTITUTO NACIONAL DE ESTATİSTICA (2013). Inquérito ao trabalho voluntário Lisboa: INE, 2012. http://www.webcitation.org/6oaWn53GF

Kaplan, M. (2001). School-based intergenerational programs. Hamburg: UNESCO Institute of Education, 2001.
Mínguez, C. (2003). Contenidos y benefícios de la educación intergenerational. In: M. Bedmar \& I. Montero (Coords.). La educación intergeneracional: un nuevo ámbito educativo (3965). Madrid: Dykinson

Maciel, Diana (2008). Género e poder local. Tese de Mestrado do Instituto Superior de Ciências do Trabalho e da Emprese, Lisboa.

Maccallum, J., Palmer, D., Wright, P., Cumming-Potvin, W., Booker, M. \& Tero, C (2010). Australian Perspectives: Community Building Through Intergenerational Exchange Programs. Journal of Intergenerational Relationships, 8(2), 113-127.

Martins, R. (2010). Análise económica do comportamento eleitoral em Portugal. Tese de doutoramento da Faculdade de Economia da Universidade de Coimbra, 2010.

Moulert, T. \& Paris, M. (2013). Social Policy on Ageing: The Case of "Active Ageing" as a Theatrical Metaphor. International Journal of Social Science Studies, 1(2), 113-123.

Oliveira, A. \& Portugal, P. (2016). Escala de Autoeficácia para a Atividade com Sentido: Encontrando sentido no envelhecimento ativo. Revista Portuguesa de Investigação Comportamental e Social, vol. 2, n.1, 3-13.

Pinazo, S. \&Kaplan, M. (2007).Los beneficios de los programas intergeneracionales. In: M. Sánchez (Coord.) Programas intergeneracionales. Hacia una sociedad para todas las edades (211-232). Barcelona: Fundavión "la Caixa".

Plutzer, E. (2002). Becoming a Habitual Voter: Inertia, Resources, and Growth in Young Adulthood. American Political Science Review, 96(1), 41-56.

Sáez, J.C. (2002). Hacia la educación intergeneracional. Concepto y posibilidades. In: J. Saéz (Coord.). Pedagogía social y programas intergeneracionales: educación de personas mayores (99-112). Málaga: Aljibe. 
Sánchez, M., Díaz, P., López, J., Pinazo, S. \& Sáez, J.C. (2008). INTERGEN. Descripción, análisis y evaluación de los programas intergeracionales en España. Modelos y buenas prácticas. Resumen ejecutivo, 2008. http://www.webcitation.org/6oaX98jXT

Sánchez, M. (2009). Intergeneracionalidad y envejecimiento activo de las personas mayores. Aportación de los programas intergeneracionales. In: A. Martinez, L. Gil, P. Serrano \& J.M. Ramos (Coords.). Nuevas Miradas sobre el envejecimiento (295-311). Madrid: IMSERSO.

Torres, A., Silva, F., Monetiro, T. \& Cabrita, M. (2005). Homens e mulheres entre a familia e o trabalho. Lisboa: Comissão para a igualdade no Trabalho e no emprego.
Villas-Boas, S.; Oliveira, A.; Ramos, N. \& Montero, I. (2016) Educação Intergeracional no quadro da educação ao longo da vida: Desafios Intergeracionais, Sociais e Pedagógicos. Revista Investigar em Educação, II Série, n. 5, 117-141

UNITED NATIONS ECONOMIC COMISSION FOR EUROPE/EUROPEAN COMISSION (2015). Active Ageing Índex 2014. http://www.webcitation.org/6oaW6y4Kb

WORLD HEALTH ORGANIZATION (2002). Active Ageing A Policy Framework. Geneve: WHO.

Zarca, B. (1990). La division di travail domestique: Poids du passé et tensions au sein du couple. Économie et Statistique, 228, 28-40.

\section{Revisión por pares abierta | Open Peer Review}

Dra. Karen McMullin. Trent University (Canada)

iD $\quad 0000-0002-1449-3550$

Dr. José Miguel García Ramírez. Universidad de Granada

iD 0000-0002-9142-6503 